\title{
Lo público en la Contaduría Pública. Sentidos y razones en la formación contable
}

The public in Public accounting - Meanings and rationales in accounting education

Recibido: 15/07/14 - Aprobado versión final: 23/09/14

\author{
María Alejandra Rodríguez Triana* \\ Natalia Andrea Gallón Vargas** \\ Jonathan Llano Uribe***
}

Resumen: en este artículo se problematiza la concepción de lo público como teoría y praxis para un ejercicio contable ético y responsable dentro de un contexto de resignificación de las prácticas de enseñanza-aprendizaje en los programas de Contaduría Pública, con el propósito de coadyuvar a la formación de profesionales contables con un alto sentido de lo público.

Palabras clave: formación contable, sentido de lo público, enseñanza-aprendizaje, Contaduría Pública.

Resumen: this paper brings into question the notion of the public as theory and praxis for an ethical and accountable accounting practice, within the framework of resignifying the teaching-learning practices in Public Accounting curricula, in order to help in training accounting practitioners with a high sense of the public sphere.

Keywords: accounting formation, sense of the public, teaching-learning, public accounting.

JEL: I21 - M49

\footnotetext{
* Joven investigadora, integrante del Grupo de Investigación en Filosofía - GIF - de la misma institución y del Grupo de Investigación Observatorio Público del Tecnológico de Antioquia, Medellín - Colombia. maria.rtriana@gmail.com

** Joven investigadora, integrante del Grupo de Investigación en Filosofía - GIF - de la misma institución y del Grupo de Investigación Observatorio Público del Tecnológico de Antioquia, Medellín - Colombia. nataliagv6@gmail.com

***Administrador en Salud Pública, joven investigador e integrante del Grupo de Investigación Observatorio Público de la misma institución, Medellín - Colombia. nathan.uribe@gmail.com
} 


\section{Contex to Rodriguez, M, Gallón, N. \& \&Lano, J.}

\section{La notion du "public" dans la licence universitaire " Comptabilité Publique ». Significations et motivations dans la formation des professionnels de la comptabilité}

Résumé: dans cet article nous abordons la notion du "public" selon une approche théorique et pratique dans le but de parvenir à un exercice de la comptabilité à la fois éthique et responsable. Cela dans un contexte de remise en question de l'exercice de l'enseignement et de l'apprentissage dans les cursus de Comptabilité Publique. Notre objectif, c'est de contribuer à la formation de professionnels de la comptabilité qui tiennent à la notion du «public ».

Mots clé: formation en comptabilité, notion du «public », enseignementapprentissage, comptabilité publique.

\section{Introducción}

Hoy en día, y desde hace algún tiempo, el mundo académico contable plasma la necesidad de una visión más consciente de los problemas sociales, culturales y públicos, que evidencie la exigencia de un profesional cada vez más humano y con sentido crítico, capacitado para analizar no sólo información numérica y contable sino también los asuntos sociales que le envuelven en su diario vivir. El rol empresarial tiene una incólume fuerza que abraza el ejercicio profesional contable, en tanto el llamado es a cuestionar esos roles y perspectivas impuestos para los contadores y las contadoras. Los esfuerzos por ubicar el ejercicio contable inmerso en esas problemáticas se deberían encaminar hacia una construcción propositiva que ofrezca soluciones.

Reivindicar el análisis sobre los espectros que atañen a la profesión atraviesa, sin duda, el sentido de lo público en el ejercicio contable a la luz de las prácticas de enseñanza-aprendizaje de la contabilidad. Lo anterior indica una reflexión profunda y crítica que reivindique el sentido de lo público entre el estudiantado respecto de su ejercicio profesional responsable, al momento de aportar a la solución de los problemas que la sociedad les exige como contadores públicos. El objetivo que tiene esta reflexión versa sobre la concepción de lo público como teoría y praxis para un ejercicio contable ético y responsable, en un contexto de resignificación de las prácticas de enseñanza-aprendizaje en los programas de Contaduría Pública.

1. Es importante tener en cuenta que en Colombia, y desde hace ya algunos años, se ha develado la construcción de una comunidad académica contable que ha profundizado en temas álgidos de las disciplinas y ciencias, tales como la epistemología, la educación, la regulación, entre otros aspectos que, desde la contabilidad, se han puesto sobre la mesa para ser debatidos, refutados y reconstruidos a la luz de nuevos postulados y nuevas visiones del mundo, propias de una sociedad dialéctica y compleja. Para tal efecto, se invita a consultar autores que se han inscrito en tal dinámica, como Mauricio Gómez Villegas, William Rojas Rojas, Danilo Ariza Buenaventura, Marco Machado Rivera, Jhon Cardona Arteaga, Édgar Gracia López, Rafael Franco Ruiz, Harold Álvarez Álvarez, Jack Araújo Ensuncho, entre otros actores principales de la historia académica contable en Colombia. 
El asunto que se presenta, además de los muchos que pueden considerarse a partir de la problemática descrita, es una obligación ética de los profesionales contables, en el sentido en que éstos deben pensar y repensar sobre lo que significa lo público en su formación como profesionales, y por supuesto en su ejercicio profesional, de tal manera que la obligatoriedad que les otorga la Ley 43 de 1990, en términos de la fe y la confianza públicas, no se traduzca simplemente en una oportunidad laboral sino en un compromiso responsable con las organizaciones productivas, sociales y estatales.

La preocupación por el sentido y el carácter de lo público se debe reconocer a la luz de varios determinantes que posibilitan su existencia, asuntos que van más allá del Estado y su gobernanza, puesto que, lo público "[...] es posible gracias a tres ingredientes fundamentales, analizados con algún detalle: el cristianismo, la ciudad de occidente y el mercado" (Uricoechea, 2001, p. 42), lo cual se debe profundizar en los referentes conceptuales de este trabajo.

Tal preocupación rebasa las formas tradicionales sobre las cuales se enseña y se educa en las facultades de contaduría pública de Colombia, puesto que aún no se ha conceptualizado suficientemente lo que se considera como público, y ello constituye un elemento difusor en el ejercicio de enseñanza-aprendizaje en Contaduría Pública.

Esta inserción del concepto problemático en la formación de profesionales contables podría mejorar sustancialmente la relación UniversidadEstado-Empresa, en la medida en que los futuros profesionales revelen un comportamiento socialmente ético y responsable, capaz de mejorar las relaciones entre el Estado y las organizaciones que lo componen.

Para dar curso a lo señalado, se parte de un análisis conceptual entre educación y formación contable, donde se da cuenta de los sustentos teóricos de los conceptos y sus prácticas, pero que a la vez son procesos interdependientes; en segundo lugar, se trata de dilucidar en torno al concepto de lo público desde puntos divergentes que rompen con la concepción liberal de asimilarlo con lo estatal y las instituciones públicas; por último, se aborda el sentido de lo público en la formación contable y cómo este componente permite la concepción de un ciudadano, de un profesional que participa y se reconoce en la esfera pública.

\section{Metodología}

Este proceso de investigación consultó un diseño de investigación cualitativo, de tal manera que aportara a comprender las categorías teóricas que dan paso a la concepción de la contabilidad desde una perspectiva menos técnica, y por tanto, la relación que existe entre la contabilidad y la vida pública. El método de investigación utilizado en el desarrollo de este proceso es el hermenéutico, pues permite hacer interpretaciones más comprensivas de la 


\section{Contex to Rodriguer, M, Gallón, N. \& \&Lano, J.}

situación problemática, a la vez que discurre un tratamiento epistemológico más detallado del problema de investigación.

Las fuentes abordadas fueron las diferentes referencias escritas que, en el mundo contable, se han dilucidado respecto del acercamiento de la contabilidad hacia lo público, más allá de la connotación de la fe pública que no hace parte exclusiva del análisis de lo público y de este proceso de investigación en particular. Igualmente se recurrió a la conversación con diferentes actores de la academia contable que han aportado a la problematización del ejercicio contable teniendo en cuenta el concepto de lo público. Las técnicas e instrumentos que apoyaron este trabajo fueron la entrevista y el cuestionario, además rastreos bibliográficos y fichas de referenciación.

\section{Resultados}

\section{Educación y formación contable: encuentros y desencuentros}

Educación y formación, aunque estrechamente relacionadas, conceptualmente aluden a significados, procesos y prácticas distintos. De este modo, y siguiendo al profesor Humberto Quiceno, logra identificarse una distinción conceptual entendiéndose que:

La educación es un concepto que ha tenido una relación clara con la institución, sea ésta entendida como un hecho social, acciones o valores (Durkheim, 1976, $p$. 64). La formación por su parte es un concepto intimamente vinculado con el sujeto, el hombre y la subjetividad (Gadamer, 1993, p. 38). La formación o formación profesional cuando nace es vinculada al trabajo, al saber sobre el trabajo y en general al saber. Saber ser, saber quién ser y saber, definen el campo de problemas de la educación, la formación y la profesión. [...] Educar no puede pensarse sin una formación y sin un saber, es decir, que lo que se diferenciaba y separaba en el capitalismo clásico hoy tiende a integrarse, de tal modo que educar es una acción que lleva a educar el quién ser (sujeto) desde un campo de saber (una profesión). (2002, p. 89-90)

La formación recae, principalmente, sobre el sujeto para configurar una subjetividad propia, unas maneras particulares de acción y pensamiento que distan de ser regentadas o impuestas; en otras palabras, la formación atañe a procesos de forma que busca el propio sujeto en distintos escenarios de la experiencia vital, lo que conduce a pensar que no necesariamente se da en la universidad con el desarrollo de una carrera o formación profesional, contrariando la idea de que es posible equiparar formación - en los términos que aquí se plantean - con formación profesional, pues ésta no logra acercarse de manera efectiva a la formación del individuo sino que, más bien, está vinculada a dinámicas que responden a un modelo económico, político y social imperante, además de cumplir con unos parámetros y exigencias estrechamente relacionados con la tendencia funcional de reproducir sujetos 
estandarizados para la producción y la división social del trabajo. En este sentido, el profesor Quijano señala que:

[...] la formación es un proceso de adquisición de la forma estética y de la forma ética de cada uno. Lo estético se produce cuando uno se interesa por su apariencia y la ética cuando se interesa por sus actos. [...] Si alguien lo forma a uno, entonces desaparece la formación porque ella es un acto libre, si a uno lo forman eso se llama dependencia, domesticación, instrucción. Lo estético y lo ético se producen al construir una forma, un estilo, unas maneras propias. (Foucault, citado por Quijano, 2007, p. 4)

Ahora bien, la educación responde a modelos institucionales imperativos que tienden a mantener un orden de cosas dado en un contexto minado por la ideología neoliberal, que propende por el pensamiento único, la mercantilización de los derechos, la cosificación del ser humano y la colonización de los saberes, en tanto impone sus propias lógicas en desmedro de la diversidad, la pluralidad y las manifestaciones divergentes de cultura de los pueblos, a la vez que se inmiscuye en la esfera educativa para la producción de conocimientos parciales que poco tienen que ver con la solución de las necesidades sociales, y el adiestramiento de sujetos que lejos están de establecer una relación dialógica, compleja y transformadora con su entorno social, político y cultural.

En este sentido, el profesor Moncayo afirma que:

El sistema educativo no puede estimarse como un mundo neutral y separado del orden capitalista, sino que siempre ha formado parte de él, cumpliendo funciones necesarias para su reproducción en campos tales como la calificación de la fuerza laboral, la formación de las élites, la transmisión y el reforzamiento de valores políticos y culturales inherentes a la dominación en muchos órdenes, y la recepción, comunicación y producción de la ciencia, la técnica y las artes. (2011, p. 2)

Por su parte, la contabilidad se ve fuertemente permeada por los paradigmas técnicos, empresariales y de mercado en sus contenidos y prácticas, en tanto que "[...] ha sido entendida, en el imaginario general, como una disciplina empírica con una visión profesional instrumentalista e ingenua de la realidad, en tanto su quehacer parece favorecer el desarrollo de prácticas rutinarias, parametrales y esquemáticas" (Martínez, 2008, p. 127). A esto el modelo educativo responde de manera efectiva enfatizando en el conocimiento técnico y registral y soslayando la investigación, el carácter epistemológico, social e interdisciplinario de la contabilidad como saber en construcción y que no está dado o contenido en leyes y manuales. En este sentido, la educación contable, tal y como se concibe hoy, podría entenderse como un dispositivo de control social, 


\title{
Contex to Rodriguer, M, Gallor, N. \& L Llano, J.
}

[...] ya que responde a las lógicas de quienes tienen el poder, se instaura en el pensamiento de los individuos para que actúen colectivamente en pro de los requerimientos del capital, aquel que está pensando en la maximización de los beneficios de quienes tienen los medios de producción. (Gallón y Rodríguez, 2013, p. 12)

Si la educación contable está al servicio de los intereses dominantes en espacios económicos, sociales, políticos y culturales, es claro que su estructura pedagógica atenta contra la emancipación del ser humano y su desarrollo crítico. Freire propone un modelo de ruptura que se direcciona a la transformación de la pedagogía tal y como ha sido sustentada. Un modelo en el que la educación sacude los cimientos dominadores y está llamada a recoger las expectativas, propuestas y problemáticas del pueblo. "La educación verdadera es praxis, reflexión y acción del hombre sobre el mundo para transformarlo". (Freire, 2007, p. 7)

La acción educativa impuesta establece contenidos académicos mecanicistas que fluyen a través de las dinámicas de producción y cosifican al ser humano, instrumentalizan lo humano. En cambio, los modelos educativos alternativos, como el planteado por Freire, entienden la práctica pedagógica como una herramienta para la liberación que ocupa un papel fundamental en la emancipación social, y tienen en cuenta que no solo libera sino que puede oprimir, en lo cual hacen un profundo énfasis, partiendo de la justificación del ser humano como un ser de adaptación al mundo y que su acción educativa, sus métodos y sus objetivos se adecuan a esa concepción.

El llamado es a integrar y entender que la práctica pedagógica es una práctica en la que se (re)piensa la sociedad, en el entendido de una revolución cultural y todo un ejercicio desalienante que se incluye en escenarios políticos y económicos. En ese sentido, Mariátegui propone que:

\begin{abstract}
[...] el problema de la enseñanza no puede ser bien comprendido al no ser considerado como un problema económico y como un problema social. El error de muchos reformadores ha estado en su método abstractamente idealista, en su doctrina exclusivamente pedagógica; sus proyectos han ignorado el íntimo engranaje que hay entre la economía y la enseñanza y han pretendido modificar ésta, sin conocer las leyes de aquélla. Por ende, no han acertado a reformar nada sino en la medida que las menospreciadas, o simplemente ignoradas leyes económico-sociales, les han consentido. (2007, p. 142)
\end{abstract}

Habida cuenta de lo anterior, se debe repensar la educación contable y cuestionar sus postulados en un contexto, no ya de certezas sino de ambigüedades e incertidumbres, a fin de que tome parte en procesos de transformación y se involucre, desde su saber y quehacer contables, en la solución de problemas en las organizaciones, pero que también sea agente que aporte a la dignificación del ser humano, al reconocimiento del otro y a la construcción de espacios y acciones democráticos y políticos. 
Es claro que la contabilidad por sí sola no tiene por qué tener el poder mesiánico de cambiar el mundo y los sujetos, pero se hace necesaria una apertura a otros saberes y a la construcción de una relación indisoluble entre teoría y praxis contables. Por otro lado, esta tarea no sólo le compete a la educación contable sino que la formación, esa acción de darse forma y de adquirir una singularidad propia, cumple un papel preponderante a la hora de concebir sujetos con sentido, críticos, autónomos y situados en una realidad compleja, conscientes de que puede ser controvertida, refutada y transformada, rebeldes que luchan contra el panóptico foucaultiano de la obediencia (De Zubiría, 2012); sujetos para la vida, para reafirmarla y descubrirse en la dramática, leve y transitoria trashumancia de la existencia.

\section{Consideraciones en torno a lo público: una aproximación}

$\mathrm{Al}$ sugerir el estudio impulsado por la academia para profundizar en el tema de lo público, reaparece en el espectro un diálogo muy fértil con lo político y lo social. De esta manera se vuelve a una de las necesidades principales de estos apartados teóricos, en cuanto se deben analizar los elementos que versan sobre la construcción de lo público: ciudadano, democracia, justicia, participación y pluralismo; una percepción crítica del asunto y altamente necesaria.

Es importante reconocer que el sentido de lo público ha variado de acuerdo con los momentos históricos, y que las nociones de la antigua Grecia sobre el tema no son las mismas que (de)construyó la modernidad. Si puntualizamos sobre los elementos anteriormente nombrados, sus variaciones han significado el declive de lo público y un desgaste en esos términos. Perdimos en las cortinas de humo modernas los avances en esa materia, sin embargo, Habermas, con su acción comunicativa en la esfera de lo público y Arendt, con su concepción de ciudadanía y otros, desde las esquinas más reconocidas, han logrado interrogar en una necesidad que hoy compromete estas líneas.

Varios autores han llevado a que la construcción del concepto se comprenda a través de momentos históricos, en los que se va dando un devenir de la noción del campo de lo público, y de otros elementos que ayudan a la estructuración de esta noción. Al dar una mirada retrospectiva sobre el origen de lo público, Rubén Jaramillo Vélez (1999) plantea que las civilizaciones antiguas (entendidas desde las castas), la construcción filosófica de los griegos, la Reforma, la Ilustración y, por supuesto, la Modernidad, son parajes históricos trascendentales en el reconocimiento de la concepción de lo público. En las civilizaciones antiguas, la casta sacerdotal parte en dos el desarrollo del concepto de público para la humanidad; sin embargo, desde la génesis de la propiedad privada, lo público se manifiesta como una suerte de contradicción social. El monopolio de la palabra y la escritura no incluía a la comunidad en general, la casta sacerdotal era la única que accedía al conocimiento, privatizado por el poder, y es en el ámbito privado donde nace la necesidad de entender lo público, y esa sensibilidad con la sociedad en términos de inclusión colectiva. 


\section{Contex to Rodriguer, M, Gallon, N. \& \&Lano, J.}

Con la polis, Grecia empieza a revolucionar la concepción de sociedad tal y como se establecía. "La Polis tenía como centro el ágora, ya no el palacio real, ya no la residencia del déspota. En efecto, aquella era el lugar en donde se reunían los ciudadanos" (Jaramillo, 1999, p. 69). El uso público de la razón, en términos kantianos, desgarra el paradigma de las letras privatizadas para ampliar su espectro hacia el entendimiento de la ciudadanía. La polis dinamiza la participación de todos aquellos reconocidos como sujetos libres, ciudadanos propietarios, toda vez que los esclavos eran excluidos aún siendo griegos; se conciben los sujetos como propiedad privada. Los ciudadanos tenían la posibilidad de participar de la palabra y tomar decisiones en aras de problematizar coyunturas concretas y de construir saberes políticos y filosóficos, para reconfigurar el concepto de justicia, ya no divina o mitológica sino universal, donde todos los ciudadanos, teniendo en cuenta las manifiestas acepciones, se reconocen como iguales en ese Estado de Derecho que desde allí se proponía; Grecia hacía uso de lo público.

Este recorrido histórico debe detener su mirada en La Reforma, "ese acontecimiento con el cual, según Hegel, se inicia el proceso de la modernidad y se impone su principio, la subjetividad" (Jaramillo, 1999, p. 71). Los reformadores recuperaron la palabra perdida en la Edad Media, atravesada por el cristianismo, este proyecto destierra el monopolio de las letras en manos de unos cuantos y abre paso a hombres, mujeres y laicos.

La modernidad moldea la nueva concepción de lo público. El movimiento de dinero marca también el curso de la historia y la construcción de la esfera de lo público. Particularmente con este, se hace necesario y constante el tráfico de noticias y la prensa en el ejercicio mercantil. Es allí donde familias poderosas de la época en Europa empiezan a apoderarse de estos primarios medios de comunicación y los incorporan a las necesidades del mercado. Nada diferente al mundo de hoy.

El mercado modifica la figura de estado que desde Grecia ya había conseguido fortalecerse. Ahora, el estado moderno se trivializa y se transforma en un sistema impositivo capaz de suplir las necesidades del capital. De acuerdo con estas dinámicas, es inminente centrar la atención en la constitución de nuevos espacios para complementar el concepto de lo público aún en construcción.

Lo público representa un panorama amplio que hace alarde de los legados griegos a su mejor manera, que se convierten en los primeros visos sobre la organización ciudadana con errores y elementos por debatir. Es lo público desde abajo y horizontal, alejado de los moldes institucionales, y reconocido a la luz de una ciudadanía constituida en las esferas de convergencia constructiva y participativa, de cara a una serie de necesidades puntuales para transformar el modelo impuesto de sociedad que nos tatuaron. Lo "público", por ejemplo, puede significar: a) relacionado con el Estado; b) la comunidad política, a menudo identificada con lo "nacional" o "popular"; c) lo accesible a todos; d) de interés para todos; e) relacionado 
con el interés compartido o el bien común; f) la importancia de la pluralidad como contenido esencial de lo público. (De Zubiría, 2006, p. 5)

Lo público como lo colectivo, pero no todo lo colectivo entendido como público. Pluralista y equitativo, que enfrente la estructura de cosas establecida y predeterminada bajo la férrea luz del control social y el ejercicio de dominación, en una lucha aún por construir, que desdeñe esas punzadas de la modernidad que ha menoscabado el legado griego ${ }^{2}$ y sigue conduciendo a la habilitación de sujetos altamente productivos y amnésicos, individualistas e instrumentales.

Es necesario reconstruir el sentido de lo público e instaurar en esa construcción percepciones emergentes que recojan en la conceptualización nuevas visiones críticas del tema. A una construcción teórica de urgente razón le atañe situar este desdén académico dentro del espectro de formación contable.

Es claro que ahondar en este estudio dará luces sobre la inquietud principal de esta construcción, la cual pondrá, de cara a las reorientaciones de este fenómeno, una serie de reflexiones que se abordarán no sólo desde la concepción de lo público sino que tocarán tangencialmente más esferas académicas, sociales y políticas permeadas por ese sentido mal entendido.

Los y las contables deben empoderarse contra-hegemónicamente en el estudio del sentido de lo público, con la sólida intención de evaluar si la universidad reconoce su valor distanciado de lo estatal o si, por el contrario, cada constructo teórico apunta a ubicar el papel de los y las contables, en términos de lo público, con nuevas aristas coyunturales que se dilucidarán en estos apartados.

\section{El sentido de lo público en la formación contable: razones e incertidumbres}

Adentrarse en la cuestión de lo público, en su importancia y sentido en la formación integral de los contadores públicos en Colombia, cobra especial interés porque permite retornar a la idea de lo público como algo polisémico y complejo que no se agota en la rígida concepción que lo afinca a una relación con el Estado o con lo ambiguo y abstracto que resulta ser lo accesible y de interés para todos. En este sentido, son los contadores y las contadoras quienes hoy deben propiciar los elementos para el análisis sobre el tema a partir del ejercicio profesional. Así lo señala Jairo Bautista:

Para la contabilidad, lo público siempre se ha constituido como un campo de obligatoria referencia, es más, podría afirmarse que lo público es el campo natural de la contabilidad, porque la legitimidad del saber contable (a diferencia del saber económico, o el sociológico) necesita de una validación en

2. El legado griego se aborda desde la condición de los hombres, si bien privados, de discutir sobre asuntos coyunturales de la sociedad y encontrarse en la pluralidad. La transición de la esfera privada a la esfera pública. 


\section{Contex to Rodriguer, M, Gallón, N. \& LLano, J.}

lo público, conceptos como la Fe Pública son en esencia las manifestaciones de la naturaleza pública de la contabilidad. $(2005, p$. 1)

De otro lado, incita a develar la casi nula y marginal presencia de lo público en la educación contable, toda vez que se le vincula con las técnicas y procesos registrales de llevar los movimientos económicos de lo que tiene que ver con las arcas del Estado o cuando se hace referencia, tímidamente, a la fe pública, alusión por demás precaria, al referirse al aval o la firma de estados financieros, certificado de ingresos, entre otros. Esta visión unidimensional no permite trascender a la esfera de lo público como un asunto que es directo e incide en el ejercicio ético de la profesión, y en la formación de sujetos ubicados en el espacio-tiempo de la fragmentación de los vínculos colectivos, de los proyectos comunes, del derrumbamiento de las fuerzas sociales conscientes y de la prevalencia de la masa anacrónica que iza la bandera del individualismo y de la indiferencia.

A la vez, adentrarse en lo público lleva a dilucidar propuestas metodológicas, curriculares y didácticas, diferentes a las que se tienen, que potencien los procesos formativos de profesionales con un alto sentido de lo público.

A pesar de ello, los análisis sobre la idea de "lo público" que subyace en la contabilidad son escasos en nuestro medio, y en ellos no se han analizado cuáles son las implicaciones de la idea de lo público en el desarrollo conceptual y regulatorio de la contabilidad. (Bautista, 2009, p. 209)

Si bien académicos e investigadores han pensado desde diversas posiciones el tema de la educación y la formación contables y han abarcado sus grandes ejes en el aprendizaje problémico - que aún persisten en el estado actual de la educación contable -, el tratamiento de lo público no ha sido tan amplio, es decir, desde la academia no se ha dado el espacio para pensar: a qué alude lo público, por qué y para qué, cómo se construye, de dónde viene, para dónde va, a qué intereses responde, qué tiene que ver con la consolidación de la democracia en la teoría y praxis políticas, cómo incide en la esfera pública el contador público en su ejercicio profesional, cómo se manifiesta lo público o qué características reviste en el Estado moderno y en el modelo neoliberal, cómo la contabilidad se inserta, en tanto lenguaje de poder y agente de realidades, valores e instituciones, en el dominio de lo público y cómo puede resignificar esa esfera pública.

En ese orden de ideas, se recalca la preponderancia de la formación pública en la medida en que contribuye a fortalecer la condición del profesional contable como ciudadano inserto en la polis, en medio de sus tensiones y contradicciones, que discurre sobre los asuntos sociales y políticos y toma abiertamente una posición, que comprende la diferencia aún cuando los intereses no son homogéneos, que contribuye a la construcción de espacios alternativos, plurales y divergentes donde se camina la palabra y 
se recrean imágenes histórico-culturales (que se identifican como sujetos espacio-temporales), a la vez que la argumentación y el criticismo se anteponen a los instrumentos mediáticos de poder, y generan una oposición materializada en hechos y mecanismos de acción social transformadora.

De cara a este panorama, repensar el papel del ser compromete un análisis que recoja las apreciaciones propias del sentir humanístico, las acepciones que gesten propuestas desde los modelos extracurriculares formativos para el entendimiento o la profundidad en la conceptualización de lo público, y, además, potenciar el aula de clase como esfera pública dentro de la academia y su incidencia en la formación contable.

Existe una suerte de tendencia dominante en los procesos de formación académica y profesional contable que antepone el hacer, la instrucción, el dato, el registro y la medición de la realidad en términos cuantitativos, el automatismo y la infalibilidad de un pensar ya predeterminado y controlado por la racionalidad productivista e instrumental, a lo que debería ser un proceso integral de educación vinculado con el pensar, la complejidad y la interdisciplinariedad que alimenten y controviertan la disciplina contable, un proceso que permita y potencie las intersubjetividades y que, a la vez, propicie los escenarios de participación y acción en el ejercicio de la palabra compartida, donde la alteridad y la singularidad propias se eleven a los vínculos comunitarios y solidarios.

[...] la contabilidad ha sido dominada por una concepción física que se representa los procesos empresariales de forma mecánica y si prestamos atención a lo que ello implica, podemos decidir investigar las razones por las cuales es necesario reconstruir la naturaleza de la contabilidad y las especificidades de la contaduría pública en Colombia o, para decirlo de una manera más científica, podemos poner en tela de juicio el núcleo conceptual o los presupuestos fundamentales de la disciplina contable en lo concerniente a su dimensión social. (Rojas, 2009, p. 12-13)

En la misma vía, esa reconstrucción y reconocimiento del ser decanta en el entendido de la figura de ciudadano que

[...] sitúa su accionar en el campo de la emancipación; es decir, lo sitúa frente a la alternativa de construir poder sin violencia, pues para ella el poder es "aquella realidad donde palabra y acto no se han separado, donde las palabras no están vacías y los hechos no son brutales, donde las palabras no se usan para velar intenciones sino para descubrir realidades y los actos no se usan para violar y destruir sino para establecer nuevas realidades. (Arendt, citada por Uribe, 2001, p. 178)

El ciudadano como actor político se sitúa en el espacio donde la lexis (palabra) y la praxis (teoría-práctica) constituyen el eje de construcción de realidades e identidades, en las que la comunidad se reconoce y participa haciendo uso 


\section{Contex to Rodriguer, M., Gallón, N. \& LLano, J.}

de la razón y de la conciencia de sí mismos como seres libres que buscan recrear escenarios para encontrarse y co-construir alternativas de vida.

De cara a ese reconocimiento del ciudadano por su ejercicio en sociedad, se resaltan coyunturas que convocan a la formación de sujeto para (re) construir al ser y potenciar su accionar a la luz de la esfera pública que, en últimas, terminará reconociéndolo como individuo sin limitaciones que hace su aparición para expresar e intercambiar abiertamente sus palabras. Ciudadanía como condición política, crítica y consciente, producto de un reconocimiento previo de la participación y transformación de los territorios, en la itinerante búsqueda de la construcción de una sociedad libre del yugo dominante opresor y la resistencia justa de los pueblos.

En este punto, la esfera pública adquiere sentido en la medida en que el ciudadano compromete su participación en el horizonte público y se ha reconocido a sí mismo como elemento base en la transformación social, toda vez que,

[...] Es el espacio en el que los ciudadanos deliberan sobre sus problemas comunes, por lo tanto, un espacio institucional de interacción discursiva. Este espacio es conceptualmente distinto al Estado; es el lugar para la producción y circulación de discursos que, en principio, pueden ser críticos frente al Estado. La esfera pública en el sentido habermasiano es también conceptualmente distinta de la economía oficial; no es un espacio para las relaciones de mercado sino más bien para las relaciones discursivas, es un foro para debatir y deliberar más que para comprar y vender. (Fraser citado por De Zubiría, 2006, p. 20)

La educación establecida, más que una imposición, ha representado la constitución de un tipo muy singular de sociedad, una sociedad de la autodestrucción del ser humano, el planeta y sus especies; una sociedad aletargada y, en ella, el derrumbamiento del reconocimiento del ser como sujeto transformador, el desgaste de la academia y la tergiversación de los sentires e intereses primeros de la universidad como epicentro de la universalidad.

Por la carencia de una educación como práctica de la libertad que enuncia Paulo Freire, porque el modelo de educación actual no enseña ni permite pensar como dice Estanislao Zuleta, o porque definitivamente necesitamos auténticamente una educación para la vida como advierte José Ortega y Gasset. (Arias, 2013, p. 5)

Potenciar el aula como manifestación de la esfera pública en la academia requiere un análisis más sustancial, un compromiso expreso de las partes para empoderarse de lo público como elemento que suscite la formación política de los y las contables en este caso puntual.

Bajo la esfera de lo público entendemos en principio un campo de nuestra vida social, en el que se puede formar algo así como opinión pública. Todos los 
ciudadanos tienen - en lo fundamental - libre acceso a él. Una parte de la esfera de lo público se constituye en cada discusión de particularidades que se reúnen en público. En este caso, ellos no se relacionan ni como hombres de negocios $o$ en el ejercicio de sus profesiones, cuyos asuntos particulares les motivarían a hacerlo, ni como compañeros con obligaciones estatutarias de obediencia, bajo disposiciones legales de la burocracia estatal. Como concurrencia, los ciudadanos se relacionan voluntariamente bajo la garantía de que pueden unirse para expresar y publicar libremente opiniones, que tengan que ver con asuntos relativos al interés general. (Habermas, 1973, p. 123)

El aula significaría en el escenario académico, la configuración de esa esfera pública que, de acuerdo con Habermas, representa la máxima participación de quienes hoy se forman en las universidades, y pese a las contradicciones y las lógicas de poder que le atañen al claustro académico, es inminente rescatar el valor de éste como escenario de liberación y emancipación, el reconocimiento del aula en la potenciación del debate y las discusiones que propendan por un saber dignificante e ilimitado, toda vez que resista a las dinámicas de castración pensante y crítica.

En esa medida, el reconocimiento del ciudadano en acción deberá comprometer una labor adicional. El debate y la discusión son ahora herramientas que esa esfera de lo público en la academia, entendida desde el aula, deberá tener en cuenta, ya que se hace expresa su importancia en los procesos de formación y educación, puntualmente contables. El aula, recreada como esfera de lo público, potencia la formación de ciudadanos, de sujetos críticos, autónomos, con sentido de lo humano y lo social, éticos y dueños de sí mimos. No obstante, los espacios extracurriculares, deslindados de las esferas de poder tradicionales e institucionalmente reconocidas, como la universidad y el aula, cobran especial relevancia como esferas públicas emergentes y alternativas, necesarias para recrear o potenciar la condición socio-política del ciudadano.

Estas herramientas fortalecerán el aterrizaje de ciertas nociones (difusas y vagas) que se han forjado al interior de los acercamientos académicos, en términos del sentido de lo público en la Contaduría Pública.

Inicialmente hay que señalar que en la disciplina contable, y aún más en la profesión ha existido una especie de convención alrededor de lo público: toda información contable sirve per se al interés público, y ese interés público es el interés de toda la sociedad [...] Una primera línea de indagación sobre lo público y la contabilidad gira precisamente en torno a la pregunta sobre el interés público que subyace a la organización profesional de la contabilidad a nivel global. (Bautista, 2005, p. 9)

El panorama no es menos alentador para los y las contables. De ahí la necesidad de potenciar las aulas como escenarios emancipadores, toda 


\section{Contex to Rodriguez, M, Gallor, N. \& \& Llano, J.}

vez que sustentan las propuestas pedagógicas alternativas de cara a la formación pública y política de los programas de Contaduría Pública del país.

\section{Conclusiones}

\section{La necesidad de no concluir}

No es garantía que la construcción teórica que emana de un proyecto de investigación logre dilucidar el concepto más acertado del sentido de lo público. La inquietud que compromete estos avances encarna en la necesidad de hacer manifiesto el gran número de nociones que se tienen al respecto y el asunto que es aún difuso y mal entendido desde la comunidad contable, aún cuando el ejercicio profesional debería pensarse con un sentido de lo público alejado de los aparatos estatales y mucho más profundo que la fe pública. En esa medida, es necesario propender por la construcción de ciudadanos capaces de moverse en la esfera pública y de nutrir el ejercicio contable. Contadores y contadoras libre-pensadores que sustenten su formación en lo público desde los ámbitos de lo sociopolítico.

El tratamiento de lo público en la formación contable quizás no se ha dado en el entendido de un constructo social y político en el ejercicio de las relaciones discursivas, de la palabra compartida y argumentada, del debate signado por la razón, de la vinculación a proyectos comunes, de la construcción y el reconocimiento del otro, de la diferencia y la pluralidad, de la legitimación de escenarios democráticos y de la formación como ciudadanos. Más bien, se ha relacionado con una asignatura de Contaduría Pública que hace referencia a cómo llevar la contabilidad en el sector oficial, y otro acercamiento es la calidad de notarios que, según la Ley 43 de 1993, es la impronta del Contador Público: la fe pública, asunto importante, pero insuficiente al vincularlo exclusivamente con la firma que certifica que la información financiera es fidedigna, verídica y se ajusta a la realidad de los hechos económicos.

El contador público como sujeto consciente, enmarcado en una realidad compleja y múltiple, no puede soslayar el compromiso y la responsabilidad que acarrea su profesión, pues ésta genera consecuencias sociales, es decir, no solo afecta al capitalista sino que afecta e incide en el destino de toda una sociedad, de ahí que concebir la Contaduría Pública como un saber-hacer hermético cuyo accionar solo puede darse en las organizaciones y, de manera parcial, desempeñar su papel operativo, es seguir insistiendo y recalcando la inutilidad de los procesos hegemónicos. 


\section{Referencias bibliográficas}

Arias, J. (2013). Al rescate del ser universitario. Una reflexión crítica en torno al extravío de la universidad contemporánea. Revista Adversia, 13, 1-10. Recuperado de http://aprendeenlinea.udea.edu.co/revistas/ index.php/adversia/article/view/18666/16022

Bautista, J. (2005). Lo público para la contabilidad y la contabilidad para lo público: caminos de investigación y alternativas de desarrollo contable. Congreso Colombiano de Contadores Públicos. Recuperado de http://contaduria.usta.edu.co/images/documentos/activos/14-6.pdf

Bautista, J. (2009). La muerte del Leviatán: lo público como problema contable. Revista Lúmina, 10, 207-223.

De Zubiría, S. (2006). Marx, Habermas, Fraser: Las tensiones de lo público. Revista Espacio Crítico, 4, 1-31. Recuperado de http://www. espaciocritico.com/sites/all/files/revista/recrt04/n4_a01.pdf

De Zubiría, S. (2012, 25 de septiembre). Investigación acción participación y epistemologías del sur. Conferencia sobre Orlando Fals Borda [video]. Cátedra Orlando Fals Borda del Departamento de Sociología de la Universidad de Nariño. Recuperado de http://www.youtube.com/ watch? $=$ SWhdkr0I8nw

Freire, P. (2007). La educación como práctica de la libertad. México: Siglo XXI Editores.

Gallón, N. \& Rodríguez, M. (2013). Alienación y educación contable: Una proximidad conceptual desde las teorías del control social hacia la reflexión crítica. Primer Congreso Latinoamericano de Estudiantes de Contaduría Pública y Administración, ALAFEC, Cuba.

Habermas, J. (1973). La esfera de lo público. Recuperado de http://148.206.53.230/revistasuam/dialectica/include/getdoc.php?id $=307 \&$ article $=328 \&$ mode $=$ pdf

Jaramillo, R. (1999). Sobre el origen de la "esfera de lo público". Revista Trans, 1, 64-90.

Mariátegui, J. (2007). Siete ensayos de interpretación de la realidad peruana. Caracas: Fundación Biblioteca Ayacucho. Recuperado de www.bibliotecayacucho.info/downloads/dscript.php?fname=069.pdf 


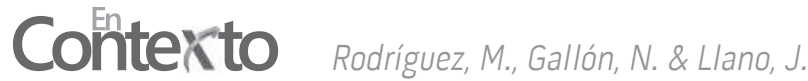

Martínez, G. (2008). La resignificación de los "contextos del conocimiento": A propósito del plan de formación contable. Perspectivas críticas de la contabilidad. "Reflexiones y críticas contables alternas al pensamiento único" VII simposio nacional de investigación contable y docencia. 127-143.

Moncayo, M. (2011). Defendamos la universidad como espacio crítico y común. Recuperado de http://www.bdigital.unal.edu.co/7387/1/ victormanuelmoncayo.20111.pdf

Quiceno, H. (2002). Educación y formación profesional. Cuadernos de Administración, 28, 89-117.

Quijano, O. (2007). En mi juventud interrumpí mi formación para estudiar Contaduría Pública. A propósito de la deformación contable. Revista Lumina, 07, 27-51. Recuperado de http://olverquijanov.jimdo.com/ art\%C3\%ADculos-ensayos-y-rese \%C3\%B1as/

Rojas, W. (2009). Contribución de las ciencias sociales y humanas a la formación del contador público. Recuperado de http:// administracion.univalle.edu.co/Comunidad/Memorias/evento1/ archivos/Contribucion $\% 20 \mathrm{de} \% 201$ as $\% 20$ ciencias $\% 20$ sociales $\% 20$ y\%20humanas $\% 20 \mathrm{a} \% 201 \mathrm{a} \% 20$ formacion $\% 20 \mathrm{del} \% 20$ contador $\% 20$ publico.pdf

Uribe, M. (2001). Esfera pública, acción política y ciudadanía: una mirada desde Hannah Arendt. Revista Estudios Políticos, 19, 165-184.

Uricoechea, F. (2001). Lo público: Historia y estructura. Revista Trans, 1, 42-54.

\section{Para citar este artículo:}

Rodríguez, M., Gallón, N. \& Llano, J. (2014). Lo público en la Contaduría Pública. Sentidos y razones en la formación contable. En-Contexto, 2, 181-196. 